\title{
Solid state NMR analysis comparing the designer-made antibiotic MSI-103 with its parent peptide PGLa in lipid bilayers ${ }^{\dagger}$
}

Erik Strandberg ${ }^{\ddagger}$, Nathalie Kanithasen ${ }^{\S}$, Deniz Tiltak ${ }^{\S}$, Jochen Bürck ${ }^{\ddagger}$, Parvesh Wadhwani ${ }^{\ddagger}$, Olaf Zwernemann ${ }^{\ddagger}$, Anne S. Ulrich ${ }^{\ddagger, \beta, *}$

${ }^{\dagger}$ This research was funded by the DFG-Center for Functional Nanostructures (E1.2)

$\$$ Institute of Biological Interfaces, Forschungszentrum Karlsruhe, P.O.B. 3640, 76021 Karlsruhe, Germany.

$\S$ Institute of Organic Chemistry, University of Karlsruhe, Fritz-Haber-Weg 6, 76131 Karlsruhe, Germany.

* Address reprint requests to Anne S. Ulrich, E-mail: anne.ulrich@ibg.fzk.de 


\section{SUPPORTING INFORMATION}

\section{Calculation of orientation from ${ }^{19}$ F-NMR data using helix model A}

Two different $\alpha$-helix models were used in the calculations of orientations from ${ }^{2} \mathrm{H}$ - and ${ }^{19} \mathrm{~F}$ NMR data. For the Ala- $\mathrm{d}_{3}$ labels we described an $\alpha$-helix (model A) using $\beta=121.1^{\circ}, \alpha=$ $53.2^{\circ}$, and $\omega=100^{\circ}$ (for definitions of these angles see the main article), as deduced from an $\alpha$-helical polyalanine model constructed in SYBYL using $\varphi=-58^{\circ}$ and $\psi=-47^{\circ}(1)$. For the $\mathrm{CF}_{3}$-Phg labels, a different $\alpha$-helical side chain geometry (model $\mathrm{B}$ ) was used, with $\beta=110^{\circ}$, $\alpha=47^{\circ}$, and $\omega=100^{\circ}(1)$. This model had been proposed based on an energy-minimized $\alpha$ helix, and was previously found to fit better than the polyalanine $\alpha$-helix to the ${ }^{19} \mathrm{~F}$-NMR data of PGLa labeled with $\mathrm{CF}_{3}-\mathrm{Phg}$ and $\mathrm{CF}_{3}-\operatorname{Bpg}(1,2)$. The results for ${ }^{19} \mathrm{~F}-\mathrm{NMR}$ data analysis using $\alpha$-helix model $\mathrm{B}$, and for ${ }^{2} \mathrm{H}-\mathrm{NMR}$ analysis using model $\mathrm{A}$ are given in the main article.

The ${ }^{19}$ F-NMR data was also fitted using model $\mathrm{A}$, and the result of the ${ }^{19} \mathrm{~F}-\mathrm{NMR}$ analysis for both models are shown in Table $\mathbf{S 1 .}$

\section{Low peptide concentration}

At $\mathrm{P} / \mathrm{L}=1: 400$, using all five labeled positions, no good fit was possible. The error plot in Figure S1 A shows a large region with similar rmsd values, but there is no orientation giving a lower rmsd than $3.1 \mathrm{kHz}$, which is unaccaptably high. From the best-fit helical curve in Figure S1 B it is clear that the best fit parameters does not reproduce the data. This is similar to the result using Model $\mathrm{B}$. However, since the MSI-103 analogue with $\mathrm{CF}_{3}-\mathrm{Phg}$ replacing Gly-11 showed a lower anitmicrobial activity, it is likely that this peptide could have a different structure or orientation in the membrane. The analysis was therefore done excluding 
this datapoint and the best-fit result using the other four data points showed a much better result. The error plot in Figure S1 C shows one clear minimum, with an rmsd of $1.6 \mathrm{kHz}$, and the orientation with a tilt angle of $94^{\circ}$ and a rotation angle of $126^{\circ}$ closely resembles the orientation found for the parent peptide PGLa (ref). This is the expected S-state orientation with peptides almost flat on the membrane surface with charged lysine sidechain pointing toward the water phase. The helical curve in Figure S1 D does not perfectly reproduce the data but the errors are much smaller than using all five data points. Using model B a similar result is found with a better rmsd of $1.2 \mathrm{kHz}$, with a tilt angle of $101^{\circ}$ and a rotation angle of $130^{\circ}$. Error plots and helical curves are shown in Figure 7 in the main article.

For $\mathrm{P} / \mathrm{L}=1: 200$ an almost identical result is found. No acceptable fit is obtained when all five datapoints are used, but excluding the label at position 11 an almost identical result was obtained as for 1:400 (Table S1, Figure S2). Using model B also a very similar result is found as for $1: 200$, with an rmsd of $1.1 \mathrm{kHz}$, a tilt angle of $102^{\circ}$ and rotation angle of $129^{\circ}$. Error plots and helical curves for the analysis with model B are shown in Figure S3.

At low peptide concentrations, compared with the results using model $\mathrm{B}$, the tilt angle is $7-8^{\circ}$ smaller and the rotation angle $3-4^{\circ}$ smaller with model $\mathrm{A}$, and the rmsd is about $0.5 \mathrm{kHz}$ higher. Thus model $\mathrm{B}$ reproduces the experimental data better and this indicates that the orientation of the phenylglycine side chain is better described by this model.

\section{High peptide concentration}

At $\mathrm{P} / \mathrm{L}=1: 50$, using all five labeled positions, no good fit was possible. For both model A and model B the best fit rmsd was unacceptable high, $3.1 \mathrm{kHz}$. The order parameter was similar in 
both cases, around 0.54 , and rotation angles were also not very different, but very different values of tilt angles were found (Table S1). Since the MSI-G11- ${ }^{19}$ F mutant result did not fit with the other data points at low concentration, an analysis at $\mathrm{P} / \mathrm{L}=1: 50$ was also performed excluding this data points. When the label at position 11 was not included, the analysis with model A gave a best fit with $\tau=99^{\circ}$ and $\rho=108^{\circ}$, and a reasonable rmsd, but the $S_{\text {mol }}$ value was unrealistically high, 1.0, which would correspond to a totally immobilized peptide. When $\mathrm{S}_{\mathrm{mol}}$ was fixed to a more normal value of 0.7 , a best fit solution was found with $\tau=99^{\circ}, \rho=$ $110^{\circ}$ and an rmsd of $1.8 \mathrm{kHz}$, which is almost the same alignment but again with a large error. Using model B, the fit gave similar values of $\tau=109^{\circ}, \rho=113^{\circ}$ and a low rmsd but also in this case $\mathrm{S}_{\mathrm{mol}}$ was 1.0 , and for $\mathrm{S}_{\mathrm{mol}}=0.7$ a too high rmsd was found. Thus, no useful fit could be obtained from ${ }^{19} \mathrm{~F}-\mathrm{NMR}$ data at $\mathrm{P} / \mathrm{L}=1: 50$. It could be possible that at this higher concentration, some additional mutant did not behave like the wild type peptide, but there was no indications from biological data that some mutant lost the activity. Since it would not be meaningful to do the analysis using only three data points, it was concluded that no orientation could be calculated for MSI-103 at high concentration in DMPC from the ${ }^{19}$ F-NMR data. 


\section{References}

1. Glaser, R. W., Sachse, C., Dürr, U. H. N., Wadhwani, P., and Ulrich, A. S. (2004) Orientation of the antimicrobial peptide PGLa in lipid membranes determined from

${ }^{19}$ F-NMR dipolar couplings of 4-CF 3 -phenylglycine labels, J. Magn. Reson. 168, 153163.

2. Afonin, S., Mikhailiuk, P. K., Komarov, I. V., and Ulrich, A. S. (2007) Evaluating the amino acid $\mathrm{CF}_{3}$-bicyclopentylglycine as a new label for solid-state ${ }^{19} \mathrm{~F}-\mathrm{NMR}$ structure analysis of membrane-bound peptides, J. Pept. Sci. 13, 614-623. 
Table S1

Best-fit orientation parameters for MSI-103 in DMPC lipid bilayers from ${ }^{19}$ F-NMR data, using two $\alpha$-helical peptide models.

\begin{tabular}{|c|c|c|c|c|c|c|}
\hline Model & $\mathbf{P} / \mathbf{L}$ & Labels used & $\begin{array}{c}\text { tilt angle } \\
\tau\left(^{\circ}\right)\end{array}$ & $\begin{array}{c}\text { rotation angle } \\
\rho\left({ }^{\circ}\right)\end{array}$ & $\mathbf{S}_{\mathbf{m o l}}$ & $\begin{array}{l}\text { rmsd } \\
(\mathrm{kHz})\end{array}$ \\
\hline \multirow{3}{*}{ A } & $1: 400$ & $\mathrm{CF}_{3}$ at $\mathrm{A} 7, \mathrm{I} 9, \mathrm{~A} 10, \mathrm{G} 11, \mathrm{I} 13$ & 42 & 129 & 0.31 & 3.1 \\
\hline & $1: 200$ & $\mathrm{CF}_{3}$ at $\mathrm{A} 7, \mathrm{I} 9, \mathrm{~A} 10, \mathrm{G} 11, \mathrm{I} 13$ & 70 & 131 & 0.32 & 2.6 \\
\hline & $1: 50$ & $\mathrm{CF}_{3}$ at $\mathrm{A} 7, \mathrm{I} 9, \mathrm{~A} 10, \mathrm{G} 11, \mathrm{I} 13$ & 88 & 99 & 0.56 & 3.0 \\
\hline \multirow{3}{*}{ A } & $1: 400$ & $\mathrm{CF}_{3}$ at $\mathrm{A} 7, \mathrm{I} 9, \mathrm{~A} 10, \mathrm{I} 13$ & 94 & 126 & 0.67 & 1.6 \\
\hline & $1: 200$ & $\mathrm{CF}_{3}$ at $\mathrm{A} 7, \mathrm{I} 9, \mathrm{~A} 10, \mathrm{I} 13$ & 94 & 126 & 0.70 & 1.7 \\
\hline & $1: 50$ & $\mathrm{CF}_{3}$ at $\mathrm{A} 7, \mathrm{I} 9, \mathrm{~A} 10, \mathrm{I} 13$ & 99 & 108 & 1.00 & 1.0 \\
\hline \multirow{3}{*}{ B } & $1: 400$ & $\mathrm{CF}_{3}$ at $\mathrm{A} 7, \mathrm{I} 9, \mathrm{~A} 10, \mathrm{G} 11, \mathrm{I} 13$ & 43 & 135 & 0.39 & 3.1 \\
\hline & $1: 200$ & $\mathrm{CF}_{3}$ at $\mathrm{A} 7, \mathrm{I} 9, \mathrm{~A} 10, \mathrm{G} 11, \mathrm{I} 13$ & 60 & 137 & 0.32 & 2.6 \\
\hline & $1: 50$ & $\mathrm{CF}_{3}$ at $\mathrm{A} 7, \mathrm{I} 9, \mathrm{~A} 10, \mathrm{G} 11, \mathrm{I} 13$ & 32 & 115 & 0.52 & 3.1 \\
\hline \multirow{3}{*}{ B } & $1: 400$ & $\mathrm{CF}_{3}$ at $\mathrm{A} 7, \mathrm{I} 9, \mathrm{~A} 10, \mathrm{I} 13$ & 101 & 130 & 0.63 & 1.1 \\
\hline & $1: 200$ & $\mathrm{CF}_{3}$ at $\mathrm{A} 7, \mathrm{I} 9, \mathrm{~A} 10, \mathrm{I} 13$ & 102 & 129 & 0.69 & 1.2 \\
\hline & $1: 50$ & $\mathrm{CF}_{3}$ at $\mathrm{A} 7, \mathrm{I} 9, \mathrm{~A} 10, \mathrm{I} 13$ & 109 & 113 & 1.00 & 0.7 \\
\hline
\end{tabular}




\section{Figure legends}

\section{Figure S1}

Figure corresponding to Figure 7 in the main article but from calculations made with helix model A (see text). (A) Error plot for MSI-103/DMPC at 1:400, using the ${ }^{19}$ F-NMR data from all five labeled positions. (B) Corresponding quadrupolar wave plot, with the best-fit curve to all five data points identified by residue numbers. (C) Error plot calculated only from the four data points of the biologically active analogues with $\mathrm{CF}_{3}-\mathrm{Phg}$ at Ala-7, Ile-9, Ala-10 and Ile13. (D) Corresponding quadrupolar wave plot, in which the data point of Gly-11 (open symbol) is not used for fitting.

\section{Figure S2}

(A) Error plot for MSI-103/DMPC at 1:200, using the ${ }^{19} \mathrm{~F}-\mathrm{NMR}$ data from all five labeled positions, and best-fit calculations made with helix model A (see text). (B) Corresponding quadrupolar wave plot, with the best-fit curve to all five data points identified by residue numbers. (C) Error plot calculated only from the four data points of the biologically active analogues with $\mathrm{CF}_{3}-\mathrm{Phg}$ at Ala-7, Ile-9, Ala-10 and Ile-13. (D) Corresponding quadrupolar wave plot, in which the data point of Gly-11 (open symbol) is not used for fitting.

\section{Figure S3}

(A) Error plot for MSI-103/DMPC at 1:200, using the ${ }^{19}$ F-NMR data from all five labeled positions, and best-fit calculations made with helix model B (see text). (B) Corresponding quadrupolar wave plot, with the best-fit curve to all five data points identified by residue numbers. (C) Error plot calculated only from the four data points of the biologically active 
analogues with $\mathrm{CF}_{3}-\mathrm{Phg}$ at Ala-7, Ile-9, Ala-10 and Ile-13. (D) Corresponding quadrupolar wave plot, in which the data point of Gly-11 (open symbol) is not used for fitting. 